\title{
Does a Test Ride Influence Attitude towards Autonomous Vehicles? A Field Experiment with Pretest and Posttest Measurement
}

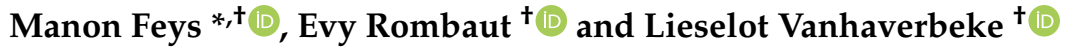

Citation: Feys, M.; Rombaut, E.; Vanhaverbeke, L. Does a Test Ride Influence Attitude towards Autonomous Vehicles? A Field Experiment with Pretest and Posttest Measurement. Sustainability 2021, 13, 5387. https://doi.org/10.3390/ su13105387

Academic Editors: Yoram Shiftan Amalia Polydoropoulou, Nikolas Thomopoulos and Valentina Rappazzo

Received: 15 March 2021

Accepted: 30 April 2021

Published: 12 May 2021

Publisher's Note: MDPI stays neutral with regard to jurisdictional claims in published maps and institutional affiliations.

Copyright: (c) 2021 by the authors. Licensee MDPI, Basel, Switzerland. This article is an open access article distributed under the terms and conditions of the Creative Commons Attribution (CC BY) license (https:// creativecommons.org/licenses/by/ $4.0 /)$.
MOBI Mobility, Logistics and Automotive Technology Research Centre, Vrije Universiteit Brussel, Pleinlaan 2, 1050 Brussels, Belgium; Evy.rombaut@vub.be (E.R.); lieselot.vanhaverbeke@vub.be (L.V.)

* Correspondence: manon.feys@vub.be

+ These authors contributed equally to this work.

\begin{abstract}
Autonomous vehicles have the potential to disrupt the mobility system. Therefore, it is important to understand attitude formation towards autonomous vehicles. The focus of this study is on the private user's technology acceptance of an autonomous vehicle. The study applies the determinants of technology acceptance to capture users' attitude towards and intention to adopt autonomous vehicles. A field experiment with 27 participants was conducted to assess changes in determinants before and after a test ride with a level 2 automated vehicle. The automated vehicle was equipped with technology that allowed a hands-off, feet-off experience on a public road in real traffic. The results show that a ride has a positive and significant effect on attitudes towards autonomous vehicles. Additionally, participants with higher ratings of technology anxiety show a remarkable increase in attitude towards autonomous vehicles after the ride compared to participants with lower levels of technology anxiety. These findings indicate that experience with a partially automated vehicle has a potentially positive effect on the acceptance of autonomous vehicles. As such, our study illustrates the importance of continuous pilot testing with private automated vehicles to increase future user acceptance of autonomous vehicles.
\end{abstract}

Keywords: autonomous vehicles; user acceptance; automated cars; field experiment

\section{Introduction}

According to the Society of Automotive Engineers (SAE), road vehicles can be classified into six levels of automation based on the capabilities of the vehicle's automated driving system and the need for a human driver to monitor and respond. The highest level (level 5) corresponds to full automation of the vehicle, where it is able to perform all driving functions under all circumstances [1]. In the literature, the terms "autonomous vehicles" and "automated vehicles" are used interchangeably. In line with Narayanan et al. [2], we use the term "autonomous vehicle" to reflect high automation (level 4) and full automation (level 5), while we use "automated vehicle" to reflect the driving assistance systems that allow for partial automation (level 2) and conditional automation (level 3). While advanced driver-assistance systems (ADAS) are available in more and more modern passenger cars, full automation is still under development. The continuous efforts of car manufacturers towards the development of fully self-driving vehicles denote the changes that await the automobile sector and by extension the effects on the travel behaviour of its users. Because fully self-driving vehicles are currently not available to the public, it is still unsure how the end consumers will respond to this new technology. Both academic research and investigations from within the sector have reported on the public's intention to adopt automated mobility. Many studies have assessed user acceptance by conducting large scale survey research where respondents express their intention to adopt and attitude towards the technology based on a textual or audio-visual description of an autonomous 
vehicle [3-11]. The results indicate that perceptions towards autonomous vehicles are mostly positive and that there is a general curiosity towards this new technology among the respondents. However, these studies also point out some recurrent safety concerns towards the reliability of the technology expressed by the respondents [5,6]. For instance, the traffic situation in which respondents feel they could trust a vehicle with self-driving technology differs. Often, respondents would be willing to use automated technology in the case of congestion or monotonous highway driving, but they would prefer to rely on their own driving skills in urban areas where unexpected hazards are considered to happen more frequently [5,7].

While these studies provide valued insights, they might capture an underestimation of the willingness to adopt autonomous vehicles. Respondents' intention to adopt an autonomous vehicle heavily and often solely depends on their imagination and the description of the vehicles by the researchers. It has been pointed out that understanding scenarios or situations involving autonomous vehicles can be difficult for respondents as they have not yet been able to interact with the technology $[4,12,13]$. Thus, it is possible that attitudes towards and intention to adopt autonomous technology could change after experiencing and using the technology [7]. Buckley et al. [14] conducted a smaller scale survey study to assess the factors of intended use in which respondents first experienced a simulated drive with an automated driving system. They argue that an interaction with an automated system can help overcome the limitations of capturing users' intended use based on a textual description of autonomous vehicles. In recent years, more pilot studies have been deployed throughout the world. The commercial availability of autonomous shuttles, in particular, has provided the opportunity for survey research in which participants first experience a ride aboard a self-driving shuttle on public roads or in semi-public environments [15-19]. While the experience gives participants a better understanding of autonomous vehicle technology, autonomous shuttles operate at low speed and represent a specific use case of future autonomous mobility services. The number of studies that capture the public perception of private autonomous vehicles in which users experience interaction with an automated driving system is limited.

This study applies an experimental setup in a non-contrived setting to capture the effect that the experience of a ride in a partially automated passenger car (level 2) can have on the intention to adopt fully autonomous passenger cars (level 5). Pretest measurements of survey responses were gathered, where the responses were given based on a description of a fully autonomous vehicle, and posttest measurements of the same survey were gathered after a ride in the automated vehicle. The items in the questionnaires conducted before and after the test ride focus on the perceptions related to full automation (level 5). The test ride provided experience with a vehicle equipped with partial automation (level 2) that allowed the driver to experience full automation related to the driving mode functions (steering and acceleration/deceleration) in a real traffic environment. We contribute to the state-of-the-art by measuring the difference in attitude and intention before and after a test ride. By including different driver profiles in the experiment, we can also investigate the size of the effect across the profiles.

This paper starts with a discussion of relevant literature in Section 2. Next, the survey as the data collection tool and the experimental setup for pretest and posttest measurement are described in Section 3. Then, the results of the survey analysis are discussed in Section 4 with a focus on the difference before and after the experience. Finally, the results of the study are reflected upon in the discussion (Section 5), and the conclusion (Section 6) summarises our main findings.

\section{Literature Review}

First, this literature review provides an overview of socio-demographic related findings from previous survey studies on user acceptance of autonomous vehicles. Sociodemographic characteristics are usually included in large scale surveys since they can provide insight into potential early user groups. Second, we present the findings from 
previous survey research in the automotive domain with a specific focus on the effect of experience with the technology on intention to adopt. Last, we briefly describe the theory behind technology acceptance models followed by their relevance in the context of automotive innovation and autonomous vehicles.

\subsection{Socio-Demographic Findings}

Previous survey studies have tapped into consumers' intention to adopt autonomous vehicles and found that men would be more likely to use autonomous vehicles than women $[3,6,7,9,11,20]$. Additionally, men would also be willing to pay more for autonomous vehicles than women [5]. Furthermore, younger people would be more likely to use autonomous vehicles than older people $[3,9,11,20]$. According to Hohenberger et al. [21], the difference between men and women can be partially explained by a difference in positive and negative feelings towards autonomous vehicles. More precisely, they found that men were more likely to associate pleasure with autonomous vehicles, while women were more likely to associate anxiety with autonomous vehicles. Additionally, the effect of anxiety on willingness to use was strongest for young women and old men [21]. With regard to scholarly degree, it has been found that people with higher levels of education would more likely use autonomous vehicles [9], particularly tech-savvy men with a higher income [22,23].

\subsection{The Influence of Experience on Affective Attitude and Behavioural Intention}

In this section, we focus on survey research that discusses the effect of having experienced new vehicle technology on the attitude towards the technology and the behavioural intention to use it.

In the study conducted by Liu et al. [24], 300 undergraduate students experienced a ride as passengers in a level 3 vehicle, operating at low speed on a campus test track. Their acceptance model predicted the behavioural intention of using autonomous vehicles and the acceptance of road tests. They measured respondents' beliefs of benefits and risks and their affective responses (positive and negative emotion and social trust) before and after the ride. A comparison of the inter-construct correlations indicated that the experience strengthened the consistency among the constructs. Additionally, the mean values of the constructs had significant changes after the experience. Notably, mean values of positive affect and perceived benefit increased, and negative affect and perceived risk decreased. The mean response value of acceptance of road tests also significantly increased, but there was no significant difference for behavioural intention after the ride.

Moták et al. [17] build on the theoretical frameworks of the Technology Acceptance Model (TAM) and the Theory of Planned Behaviour (TPB) to capture the intention to use autonomous shuttles and extended the models with the constructs group norm, positive affective attitude and confidence. They collected survey data from visitors at a hospital campus. First wave responses were based on a description of an autonomous shuttle. In a second wave, after an autonomous shuttle was introduced on the campus, visitors who experienced a ride with the vehicle were approached and subjected to the same survey. A comparison of the mean values for the constructs perceived usefulness, behavioural control, group norm, positive affective attitude, and confidence show significant difference for the respondents in the two waves. In addition, intention to use the shuttle showed a significant increase. Introducing shuttle experience as a predictor in the hierarchical regression model shows that it is one of the significant predictors of behavioural intention. Their study leads them to consider that experience (even partially) replaces the explanatory value of perceived behavioural control and confidence.

Rahman et al. [25] conducted a survey study based on TAM, TPB and the Unified Theory of Acceptance and Use of Technology (UTAUT) to capture behavioural intention to use advanced driver-assistance systems (ADAS). They used two data collection approaches to determine the validity of the models. The first approach was an online survey providing respondents with the description of two ADAS technologies. The second approach included 
the recruitment of participants to take part in a simulated driving experience of a level 2 vehicle. Results indicated that participants who used the driving simulator showed a significantly higher intention to use driver assistance technology compared to participants who only received a description of the system.

\subsection{Capturing Intention to Adopt with Technology Acceptance Models}

Theoretical acceptance models have often been applied to capture behavioural intention to adopt new vehicle technology and understand how intention to adopt is affected by different factors. These models also formed the basis for survey studies in the context of alternative fuel technology [26] and driver assistance technology [8,25]. In this section, we briefly describe the building blocks of these theoretical acceptance models and elaborate on the findings from recent survey research that applied the models to capture the intention to adopt autonomous vehicles. Figure 1 provides a visual overview of the models and their constructs.

The Technology Acceptance Model (TAM) [27] describes a sequential process of an individual's intention to use a new type of information technology. The two main determinants that affect behavioural intention are perceived usefulness and perceived ease of use. Perceived usefulness is defined as the extent to which an individual believes that the new technology will benefit one's performance. Perceived ease of use is the degree to which an individual is convinced that one can easily master the use of the new technology. TAM further theorises that technology-specific attributes, individual differences, and social influences affect the formation of perceived usefulness and perceived ease of use [28].

In recent survey research, TAM has been adapted to the setting of autonomous vehicles in order to capture user acceptance and understand the determinants that affect users' intention to use autonomous vehicles $[14,17,29-33]$. In these studies, perceived usefulness has consistently been reported as a significant predictor of intention to use autonomous vehicles [14,17,30-33]. The effect of perceived ease of use has also been analysed, but it was not always found to be a significant predictor [14,17,32]. However, Zhang et al. [33] found that perceived ease of use has a significant influence on users' attitude formation towards autonomous vehicles, and $\mathrm{Xu}$ et al. [32] found that perceived ease of use becomes a significant predictor of behavioural intention after respondents experienced a ride as passengers in a highly automated vehicle.

The Theory of Planned Behaviour (TPB) states that the three factors-attitude (positive or negative affect), subjective norm (social influence), and perceived behavioural control (ease or difficulty to perform)—affect a person's behavioural intention [34]. Adjusted to the context of autonomous vehicles, Moták et al. [17] and Buckley et al. [14] found all three factors to be significant predictors of behavioural intention to use.

Building on TAM and TPB, the Unified Theory of Acceptance and Use of Technology (UTAUT) posits that the factors performance expectancy (or perceived usefulness), effort expectancy (or perceived ease of use), and social influence predict behavioural intention to use and that facilitating conditions and intention-to-use affect actual technology use [35]. Later, the model was extended with a direct influence of facilitating conditions on behavioural intention, and the addition of three other factors: hedonic motivation (perceived enjoyment), price value, and habit [36].

Based on the first UTAUT model, Leicht et al. [37] found that performance expectancy, effort expectancy and social influence are significant predictors of the intention to purchase an autonomous car. In a different set up, where participants first had the experience of a ride in an autonomous shuttle, Madigan et al. [38] also found that performance expectancy, effort expectancy, and social influence have significant effects on the respondents' behavioural intentions to use autonomous shuttles. Later, the same set up was applied in a followup study and survey constructs were based on the second UTAUT model, including the factor hedonic motivation [16]. Results show that performance expectancy, social influence, facilitating conditions, and hedonic motivation were significant predictors of behavioural intention to use. Moreover, hedonic motivation was found to be the strongest predictor, 
while in contrast to the first study, effort expectancy was not found to be a significant predictor [16].

In addition to the relationship between perceived usefulness and perceived ease of use on intention to use in TAM-based research, several studies have included other factors believed to affect intention to use or its predictors in the context of user acceptance of autonomous vehicles. Choi and Ji [30] estimated the effect of perceived risk and trust in autonomous vehicles on behavioural intention. They found that perceived risk did not have a significant effect on behavioural intention. However, trust had a significant positive effect on perceived usefulness and behavioural intention and a negative effect on perceived risk. Moreover, Buckley et al. [14] found that introducing trust as a distinct factor that affects behavioural intention increases the explained variance of intended use.

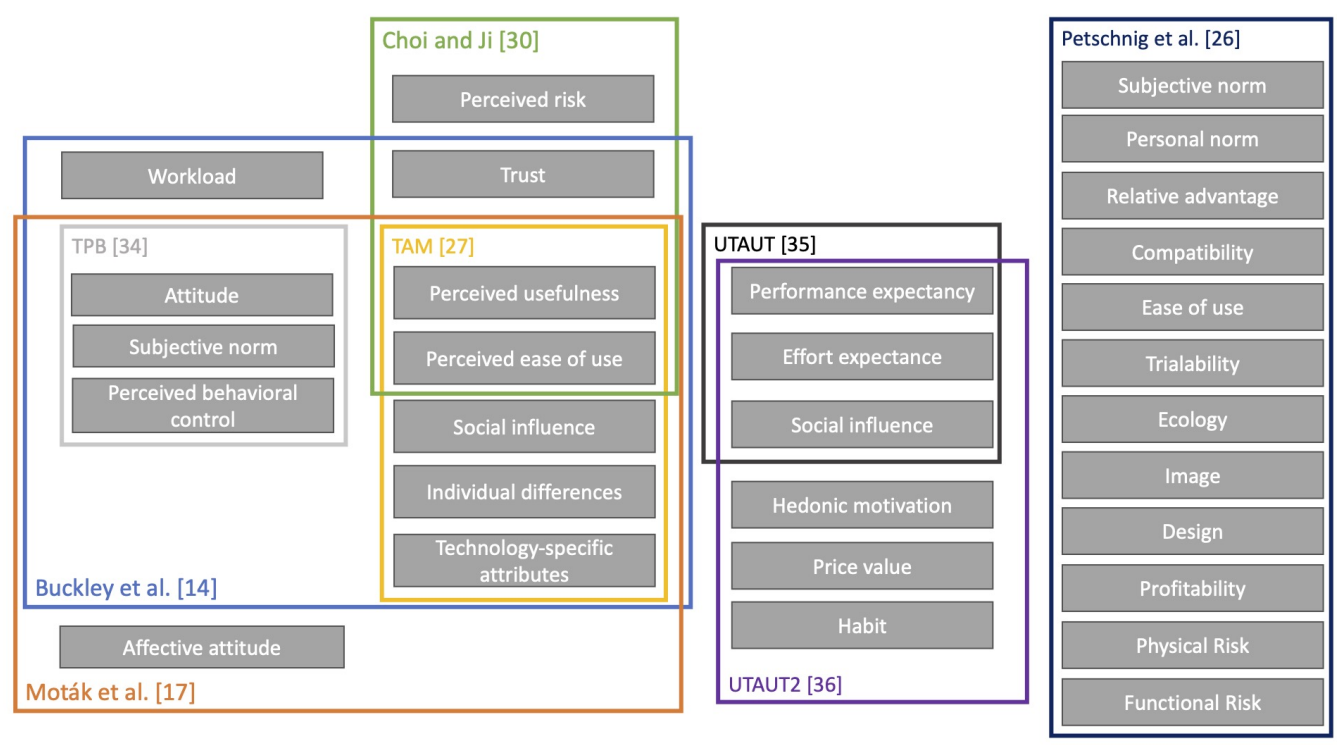

Figure 1. Overview of the technology acceptance models and their constructs discussed in Section 2.3.

As an extension to both TAM and TPB, Moták et al. [17] included the variable positive affective attitude towards autonomous shuttles and found it to be a significant predictor. The survey study conducted by Haboucha et al. [4] also shows that positive affective attitude towards autonomous vehicles is a strong indicator for intended use. In their research on the adoption of alternative fuel vehicles, Petschnig et al. [26] conducted a survey search based on the theory of innovation diffusion by Rogers [39] and the theory of reasoned action by Fishbein and Ajzen [40]. Both theories state that user adoption is preceded by attitude formation. Attitude formation is in turn formed by different innovation characteristics. Petschnig et al. [26] point out that their acceptance model is similar to TAM as it also relies on a sequential process from attitude formation to adoption behaviour. Their results confirm that attitude is a strong indicator for intention to use. Similarly, Yuen et al. [41] found that the determinants of innovation diffusion theory explain the perceived value of autonomous vehicles, which positively affects public acceptance of autonomous vehicles together with trust in autonomous vehicles.

Lastly, Zhang et al. [33] extended TAM to represent the role of initial trust as a predictor of attitude towards autonomous vehicles. They refer to initial trust as the level of trust that people place in new technologies before having interacted with them. Their results show that perceived ease of use and initial trust are predictors for attitude towards autonomous vehicls, and in turn, a positive attitude has a positive effect on behavioural intention to use autonomous vehicles.

The previous studies show that technology acceptance theory and measuring its constructs in the context of autonomous mobility are useful in large scale survey research and help to identify the important factors that will drive user acceptance of autonomous 
vehicles. The technology acceptance models were originally intended to measure acceptance of and intention to use IT systems. While we can assume a certain familiarity of the public today with computers and their applications, this is not yet the case for autonomous vehicles. Most studies rely on respondents' imagination of using this innovative technology that is currently out of reach. A few studies set out to overcome this limitation to a certain extent by providing respondents the opportunity to experience autonomous driving; for instance, as a driver in an automated driving simulator [14,25] or as a passenger in a level 3 passenger vehicle on a test track with a safety operator [24,32]. These setups give participants a more tangible experience of automated driving features.

The current survey study adds to the knowledge by focusing on the effect of experiencing a ride in an automated vehicle in a real traffic situation on the attitude towards and the intention to adopt fully autonomous passenger cars in the future. Our contribution lies in the comparison of the pretest and posttest measurement of constructs that are relevant in understanding behavioural intention to adopt privately-owned autonomous vehicles.

\section{Materials and Methods}

The aim of this study is to investigate if the experience of a ride in a partially automated vehicle, which allows to simulate full automation related to the driving mode functions (steering and acceleration/deceleration) on public roads, has an effect on constructs related to the acceptance of fully autonomous vehicles. To this end, we conducted a field experiment with pretest and posttest questionnaires. First, the respondent filled in a questionnaire to measure perceptions towards autonomous vehicles. Then, the respondent was invited to drive a partially automated passenger car (level 2). After the test ride, the respondent was asked to complete the second questionnaire.

\subsection{Survey Constructs and Items}

Based on the insights of previous research into vehicle technology acceptance, we identified several constructs that are relevant in understanding behavioural intention to adopt privately-owned autonomous vehicles and are potentially affected after an experience with an automated vehicle. The constructs perceived usefulness, perceived ease of use, attitude, and intention to adopt represent the building blocks of technology acceptance and are related to the TAM [27] and the TPB [34]. To strengthen these models and the understanding of underlying determinants that shape perceived usefulness and perceived ease of use, extensions in the context of information technology have been proposed and validated [28]. While these extensions are often not directly applicable, we believe that the constructs image [29], subjective norm [29], result demonstrability [41], (computer) anxiety [29], and perceived enjoyment are relevant determinants that can be adjusted to fit the context autonomous technology acceptance. In the framework proposed by Petschnig et al. [26], several of these determinants are presented as innovation characteristics of alternative fuel vehicles that affect attitude formation. In the context autonomous vehicles, we further included physical risk, functional risk [26], security risk [5,42], comfort benefit $[29,43]$, and trust $[30,41,43]$ as relevant determinants. To complete the selection of constructs related to the perception of autonomous vehicles, we added the construct personal norm to reflect the moral obligation felt to improve traffic safety and optimise traffic flow $[5,26]$.

Additionally, we believe that the perceptions towards autonomous vehicles based on a description are shaped by a person's general stance on new technologies. Within the context of information technology, Meuter et al. [44] identified computer anxiety as a negatively influencing factor on a person's perception and use of personal computers. They argue that the relevance can be extended to anxiety towards technology in general. Therefore, they describe technology anxiety as "a user's state of mind regarding their ability and willingness to use technology-related tools" [44] (p. 900). Mcknight et al. [45] argue that trusting stance and faith in general technology positively affect trust in a specific technology. Faith in technology, or the belief that technology is reliable and helpful, and a 
trusting stance towards technology, or the belief that technology will result in positive results, together form general trust in technology [45]. Because an autonomous vehicle requires the functioning of technological components and processes in order to drive itself, we believe that the measurement of the general technology stance of participants could provide insights into the underlying differences across participants perceptions towards autonomous vehicles.

The full list of constructs, items, and references is presented in Appendix A. The items related to the general technology stance were only included in the first survey before the ride.

\subsection{Measurement and Analysis}

The survey items were translated to Dutch and, if necessary, adapted to fit within the context of autonomous driving. The survey was first pilot tested outside the scope of the study, and if needed, the phrasing of the items was adjusted. In line with the scaling of the original measures, a 7-point Likert scale ranging from strongly disagree (1) to strongly agree (7) was used for every item. Negatively phrased items were re-coded before the average of the item scores was used to compute the construct score.

The effect of the experience was evaluated through comparison of the scores of the constructs related to the perception of autonomous vehicles before and after the automated ride with paired-samples $t$-tests, at significance level $\alpha=0.05$, in $\mathrm{R}$. If the pretest-posttest differences of the constructs did not meet the normality assumption, Yuen's trimmed $t$-test for dependent samples was used as a robust alternative to test significance between the differences and compute confidence intervals [46].

To explore whether the experience has a potentially stronger effect on participants at different levels of the factors technology trust and technology anxiety, we implemented a two-staged approach. First, we computed the correlation between the factors technology trust and technology anxiety and the pre- and post-score difference of the constructs. Then, we retained the correlation coefficients with at least a moderate effect size $(r>0.40)$ and visually assessed the relation between the discretised values of the factor and the score of the construct.

\subsection{Procedure}

The experiment was conducted in June 2017 and expanded over three days. Prior to the experiment, we sent out an invitation through social media to recruit participants. In the communication, we briefly informed potential candidates about the pilot study and invited them to fill out a recruitment survey to gather socio-demographic and driving-related data. Additionally, as per legal requirements, all of the participants needed to hold a valid driving licence in order to take part in the experiment. Using the data from the recruitment survey, we invited 30 candidates to participate in the study. The candidates varied in age, gender, and educational level but also differed in terms of driving frequency, experience with advanced driver assistance systems, and usage of contemporary technological tools (desktop or laptop, smart phone, tablet, and GPS). During the study, 27 persons were able to take part in the experiment, including the pretest questionnaire, the test ride with the automated vehicle, and the posttest questionnaire.

The experiment for each participant was structured in the same way. First, the participant filled out the questionnaire to assess his or her attitudes and perceptions towards autonomous vehicles. The respondents filled out the questionnaire in an environment separated from the test ride vehicle, as not to be influenced by its design or features. The introduction of the questionnaire included a description of a fully autonomous vehicle. Respondents were asked to imagine the use of a fully autonomous vehicle while completing the questionnaire.

Subsequently, the participants were invited into the automated vehicle equipped with driver assistance technology that allows the driver to initiate an automated driving mode in which the vehicle takes over both the steering wheel and the pedals for acceleration and 
breaking. The participants experienced autonomous driving by driving a level 2 automated vehicle for approximately $23 \mathrm{~km}$ and $20 \mathrm{~min}$ in a real life driving environment. When activated, the automated driving mode takes over steering, acceleration and deceleration, braking, and starting after standstill within the lane. A visual sign on the dashboard indicates when the automated driving mode can be activated and an audio signal warns the driver in case manual take-over is needed. When the automated driving mode was available, the participant was instructed to activate it and give control over to the car by loosening their grip off the steering wheel and taking their feet of the pedals. After a short briefing on the use of the automation system and its limits, the participant was informed to stay alert and monitor the driving situation during the automated driving mode. Thereafter, the participant was invited to start the test ride following a predetermined route. A researcher familiar with the vehicle and the route remained in the passenger seat during the ride. If needed, specific instructions were repeated to the participant.

After the test ride, the respondent completed the second questionnaire, which included the same questions on perceptions and attitudes towards fully autonomous vehicles as the first questionnaire.

\subsection{Driving Scenario}

The automated driving mode could only be activated when available during certain driving conditions. Therefore, a specific route was predetermined, and every participant was instructed to follow the same route (Figure 2). The route was chosen in such a way that the automated driving mode could be activated during the majority of the 20 min ride. The roads had clear lane markings, which allowed the assistance system to detect the lane and steer the vehicle to remain in the centre of the lane. The test rides were undertaken during the day but not during morning or evening peak hours as to avoid situations of heavy traffic and congestion.

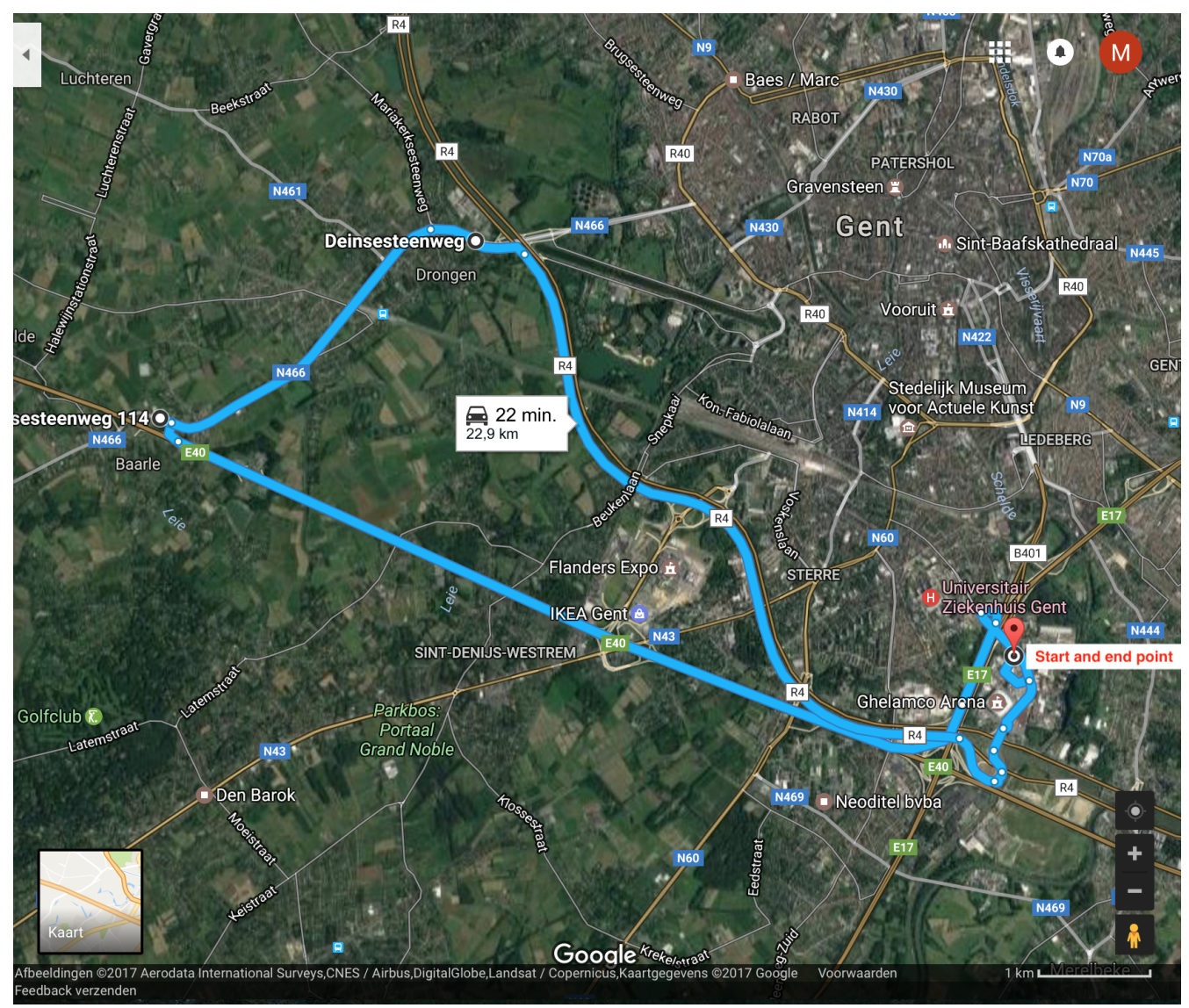

Figure 2. Screen shot of the route that all participants took during the ride taken from Google Maps. 


\section{Results}

\subsection{Sample Characteristics}

The 27 participants had a mean age of 35.15 years $(S D=16.72, \min =20, \max =74)$; fourteen participants were female and thirteen were male (Table 1). At the educational level, two participants had a high school degree, eight a bachelors degree, fourteen a masters degree, and three a doctoral degree. As per legal requirements, all of the participants held a valid driving licence. Eleven participants drove a car on a daily basis, seven on a weekly basis, seven a few times a month, and two a few times a year. Participants were also asked to indicate their experience with advanced driver-assistance systems (ADAS) including park distance control, park assist, cruise control, adaptive cruise control, adaptive cruise control with stop and go function, lane departure warning and lane keeping assist. The experience with ADAS was diverse across participants: ten participants had no prior experience with ADAS, four participants with one system, four participants with two systems, five participants with three systems, and four participants with four or more systems. Among the participants, seventeen had prior experience with automatic gears. To get an idea of the technology savviness of the participants, they had to indicate if they were familiar with one or more of the following technological applications: laptop or desktop, smartphone, tablet, and GPS. Sixteen participants indicated to be familiar with all technological applications presented. Eight participants indicated familiarity with three applications, and three participants with two applications.

Table 1. Participant sample characteristics.

\begin{tabular}{ll} 
Partcipants, $\mathrm{n}$ & 27 \\
Age in years, M (SD) & $35.15(16.72)$ \\
Gender (ref: female), $\mathrm{n}(\%)$ & $14(51.85 \%)$ \\
Degree (ref: high school or lower), $\mathrm{n}(\%)$ & $2(7.41 \%)$ \\
Driving frequency (ref: daily), $\mathrm{n}(\%)$ & $11(40.74 \%)$ \\
Experience with ADAS (ref: no experience), $\mathrm{n}(\%)$ & $10(37.04 \%)$ \\
Experience with automatic gears (ref: no experience), $\mathrm{n}(\%)$ & $10(37.04 \%)$ \\
Technology savviness (ref: familiar with all applications), $\mathrm{n}(\%)$ & $16(59.26 \%)$ \\
\hline
\end{tabular}

\subsection{The Influence of Direct Experience}

Figure 3 shows the mean response values of the technology acceptance related constructs that were measured before (red) and after the ride (green). Out of fifteen constructs, ten had significant value changes after the experience. Attitude $(\Delta M=0.66$, $t(26)=6.15, p=0.002, r=0.77)$, trust $(\Delta M=0.52, t(26)=1.89, p=0.07, r=0.35)$, functional risk $(\Delta M=0.61, t(26)=4.17, p<0.001, r=0.63)$, physical risk $(\Delta M=0.62, t(26)=3.95$, $p<0.001, r=0.61)$, security risk $\left(\Delta M_{\text {trim }}=0.76, T_{y}(16)=2.73, p<0.05, r=0.28\right)$, perceived ease of use $(\Delta M=1.07, t(26)=6.67, p<0.001, r=0.79)$, perceived enjoyment $(\Delta M=1.11$, $t(26)=6.24, p=0.001, r=0.77)$, result demonstrability $(\Delta M=0.70, t(26)=3.26, p=0.003$, $r=0.54)$, and subjective norm $(\Delta M=0.24, t(26)=2.18, p=0.04, r=0.39)$ increased. Negatively phrased items in the risk constructs were inverted. Therefore, an increase in risk is to be interpreted as reduction in risk perception towards autonomous vehicles. Autonomous vehicle (AV) anxiety $(\Delta M=-1.21, t(26)=-6.16, p=0.001, r=0.77)$ decreased.

Comfort $\left(\Delta M_{\text {trim }}=0.43, T_{y}(16)=1.59, p=0.13, r=0.19\right)$, image $\left(\Delta M_{\text {trim }}=0.31\right.$, $\left.T_{y}(16)=1.67, p=0.11, r=0.20\right)$, personal norm $(\Delta M=0.28, t(26)=1.51, p=0.14)$, and intention to adopt $(\Delta M=0.30, t(26)=1.67, p=0.11, r=0.31$ ) show non-significant increases. Notably, perceived usefulness $(\Delta M=-0.05, t(26)=-0.28, p=0.78)$ shows a slight nonsignificant decrease after the experience. 


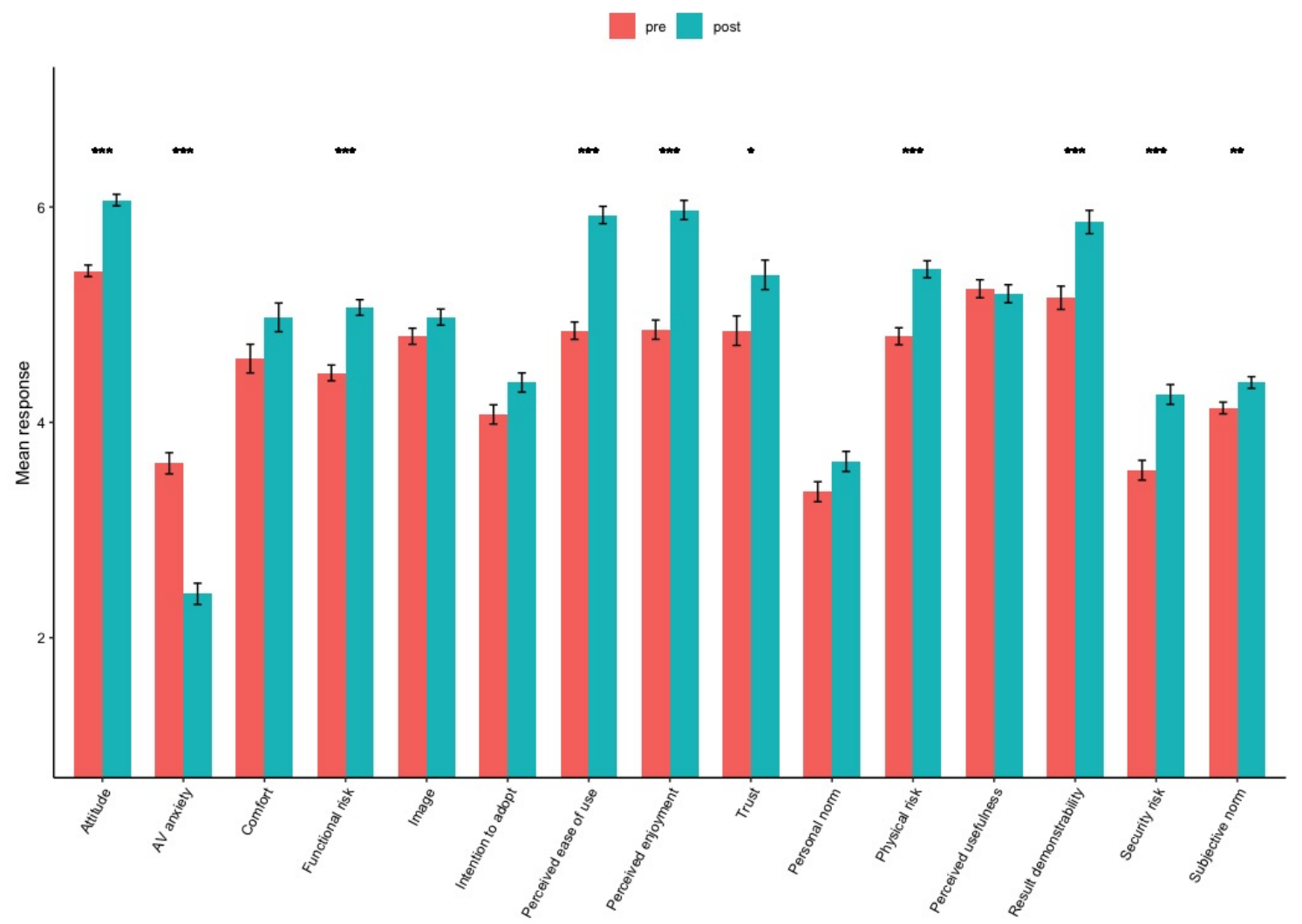

Figure 3. Mean values of the constructs before (left bar) and after (right bar) the AV experience. Error bars are $95 \%$ confidence intervals. ${ }^{*} p<0.1 ; * * 00.05 ;{ }^{* * *} p<0.01$.

\subsection{General Technology Stance}

Table 2 shows the correlation coefficients between the pre- and post-score differences of the acceptance constructs and the factors technology trust and technology anxiety. We found a moderate effect size between technology trust and intention to adopt $(r=-0.45)$ and between technology anxiety and attitude $(r=0.42)$.

Table 2. Correlations between the pre- and post-score differences of the acceptance constructs and the factors technology trust and technology anxiety. Moderate effect size in bold.

\begin{tabular}{lrr}
\hline & Technology Trust & Technology Anxiety \\
\hline Attitude & 0.01 & $\mathbf{0 . 4 2}$ \\
AV anxiety & -0.25 & -0.19 \\
Comfort & 0.36 & 0.11 \\
Functional Risk & -0.21 & 0.13 \\
Image & -0.34 & -0.37 \\
Intention to adopt & $-\mathbf{0 . 4 5}$ & 0.06 \\
Perceived ease of use & -0.11 & 0.34 \\
Perceived enjoyment & 0.06 & 0.07 \\
Personal norm & -0.22 & -0.30 \\
Physical risk & 0.07 & 0.21 \\
Perceived usefulness & 0.34 & 0.07 \\
Result demonstrability & 0.25 & 0.31 \\
Security risk & -0.09 & -0.05 \\
Subjective norm & 0.15 & -0.01 \\
Trust & -0.38 & 0.03 \\
\hline
\end{tabular}


To explore whether the experience with the automated vehicle had a more pronounced effect on participants at different levels of self-expressed general trust in technology and technology anxiety, we discretised the scores of these factors into three categories. Using the cut function in $R$, the range of the scores is divided into three intervals of equal length. For technology trust, the range of the scores was between 4 and 5.86, and the length of each interval was 0.62 . For technology anxiety, the range was between 1 and 4.56 , and the interval length was 1.19. The resulting categories were labelled low, medium, and high. These categories were then plotted against the before and after scores for intention to adopt (Figure 4) and attitude towards autonomous vehicles (Figure 5), respectively. Figure 4 indicates that only a few participants with low and medium levels of technology trust had a lower intention to adopt after the experience. However, amongst the participants with a high level of trust, most had a lower score for intention after the experience. Figure 5 shows that while attitude towards autonomous vehicles increased for most of the participants, the group of participants with higher scores of technology anxiety had a more pronounced increase in attitude towards autonomous vehicles after the test ride. Among the five participants with higher scores of technology anxiety, four were female.

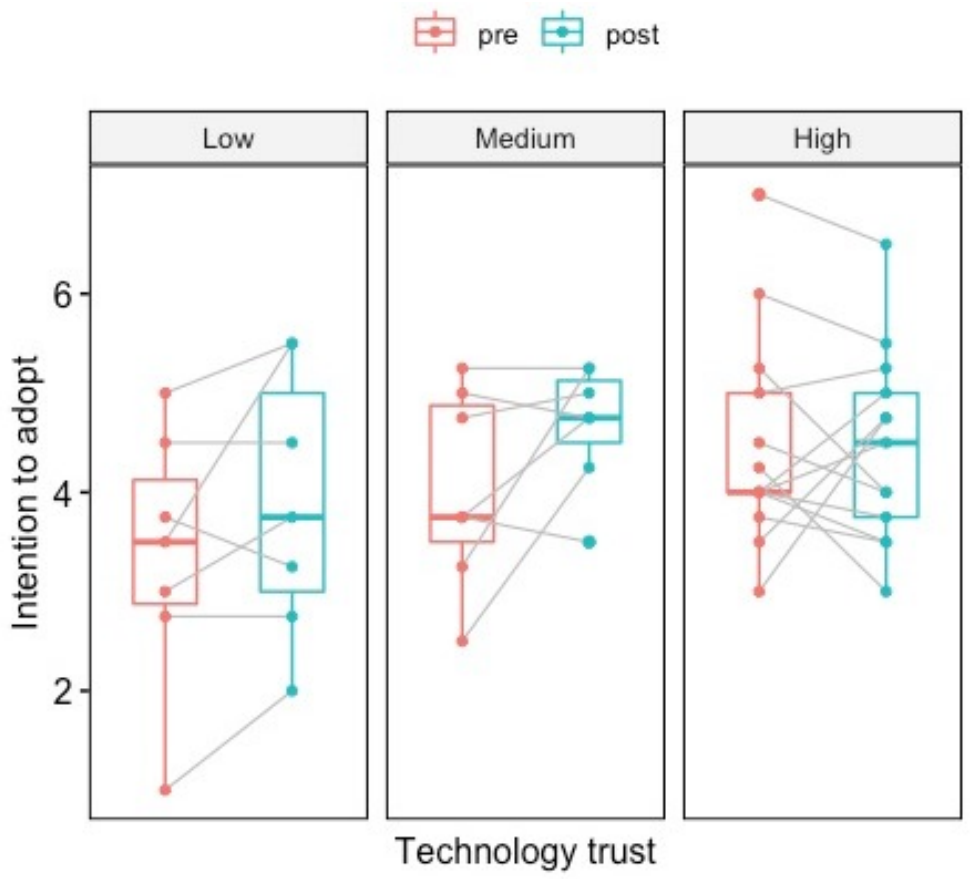

Figure 4. Boxplot of scores for intention to adopt autonomous vehicles categorised into three levels of technology trust: low [4-4.62] $n=7$; medium [4.62-5.24] $n=7$; high [5.24-5.86] $n=13$. The dots represent the scores for intention to adopt of the participants. The grey lines connect the pre and post values belonging to the same participant. The intervals of technology trust were obtained using the cut function in $\mathrm{R}$ and $\mathrm{n}$ denotes the number of participants in each category. 


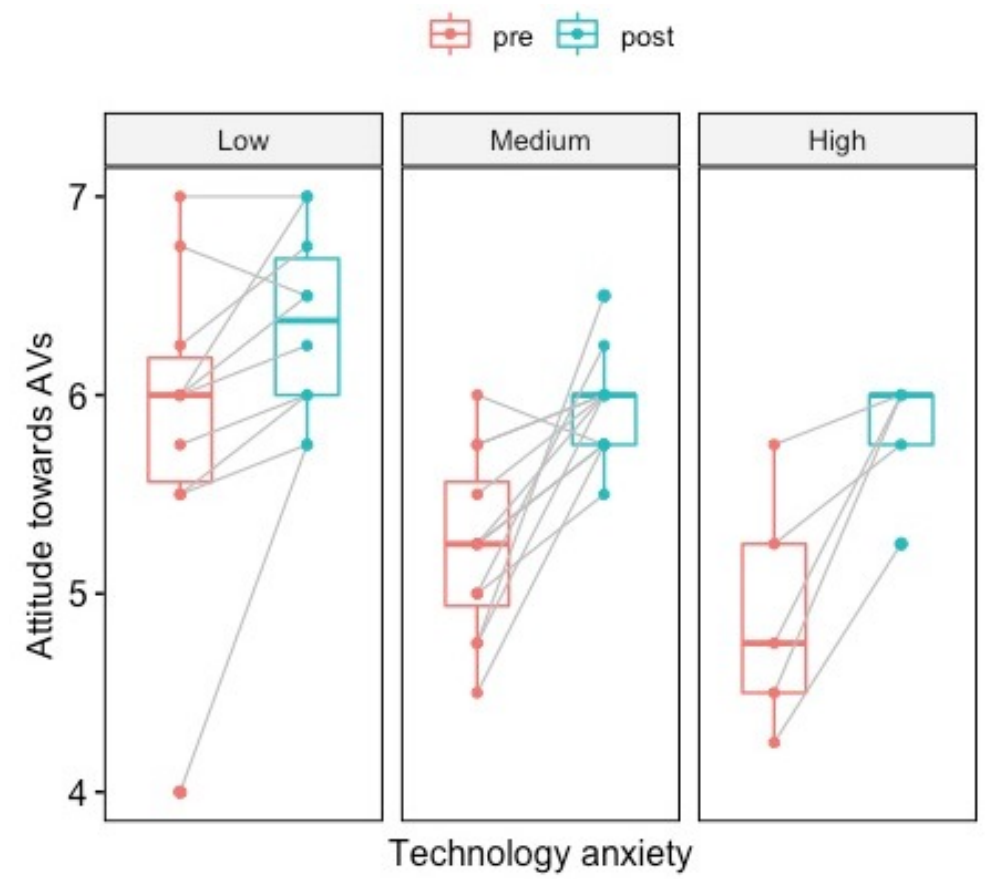

Figure 5. Boxplot of scores for attitude towards autonomous vehicles categorised into three levels of technology anxiety: low [1-2.19] $n=10$; medium [2.19-3.37] $n=12$; high [3.37-4.56] $n=5$. The dots represent the scores for attitude towards autonomous vehicles of the participants. The grey lines connect the pre and post values belonging to the same participant. The intervals of technology anxiety were obtained using the cut function in $\mathrm{R}$, and $\mathrm{n}$ denotes the number of participants in each category.

\section{Discussion}

\subsection{Reflection on the Findings}

The results show significant changes for the majority of the measured constructs before and after the ride in a level 2 automated car. Additionally, the effect size of the constructs attitude, perceived ease of use, perceived enjoyment, AV anxiety, functional risk, physical risk, and result demonstrability indicate that the effect of the experience is substantial in practical terms. In particular, the increase of attitude towards autonomous vehicles before and after the ride is important to note within the context of acceptance research. Previous research has confirmed that attitude is an important predictor of intention to adopt. Thus, our findings indicate that experience with autonomous technology has a potentially positive effect on the acceptance of autonomous vehicles. Further comparison of the before and after attitudes towards autonomous vehicles shows that participants with higher levels of technology anxiety had a remarkable increase in attitude after the ride. This suggests that a participant's level of technology anxiety, in general, should be taken into account when evaluating their attitude towards autonomous vehicles through survey research if the experience of a ride in an automated vehicle is not feasible. We also noted that four out of the five participants with a higher level of technology anxiety were women. Our findings suggest that in efforts to increase the public's intention to adopt, it could be beneficial to target women specifically for experience through pilot testing as it is more likely that the experience will have a considerably positive effect on their attitude to autonomous vehicles. Moreover, the large effect size of the increase in perceived ease of use and decrease in AV anxiety indicate that the test ride has given the participants more confidence in their ability to interact with an autonomous driving system. Research conducted by Hohenberger et al. [47] found that for respondents with higher levels of self-enhancement, or a stronger belief in one's abilities, the negative effect of anxiety on the intention to use automated vehicles is smaller. Therefore, continuous pilot testing is advised in order to allow the public to experience the technology [12]. This 
will be important for the promotion of autonomous vehicles, especially towards people with lower levels of self-enhancement and trust [48].

Next, we discuss some of the non-significant changes we found in this study. First, perceived usefulness showed a decrease before and after the test ride, and the increase in comfort was not substantial. This could indicate that the possibility of performing nondriving related tasks while in an autonomous vehicle and the benefit of time that can be gained were not made apparent during this experiment. This is important to note because perceived usefulness has been consistently found to be a strong predictor of behavioural intention in the context of autonomous vehicle acceptance.

Second, the low mean scores for personal norm suggest that participants do not feel a moral obligation to choose an autonomous car over a conventional car. This could entail that the increase in traffic safety, which is portrayed as one of the main benefits that can be brought about by autonomous vehicles, was not evident. If that was the case, the construct did not capture the intended association towards autonomous vehicles. On the other hand, it should be considered that, regardless of the presumed safety benefit, the participants believe it safer to be able to drive themselves and take control of the vehicle in case of precarious traffic situations. As Payre et al. [7] show, contextual acceptability significantly affects the intention to use automated vehicles. Their survey results showed that participants preferred autonomous driving in monotonous or stressful driving situations, like on the highway or during congestion, but they would use it less often in urban areas. The route of the test ride included both highway and off-highway roads; however, we were not able to include roads passing through urban areas.

Lastly, we found that the increase in intention to adopt autonomous vehicles after the ride was not substantial and not significant. The construct was adapted based on the intention of Petschnig et al. [26] to adopt alternative fuel vehicles. These items are, however, focused on the intention to buy the vehicle in the (near) future. The rather strong commitment of purchase instead of use could explain the overall lower mean score in intention to adopt. It could also clarify why the difference before and after the ride was not significant, in contrast to the significant difference in attitude. It can be argued that in this stage of the technology, it is still too early for users to contemplate the intention to buy. Therefore, intention to adopt might be better captured by referring to one's willingness to use an autonomous vehicle in the future (see $[7,14,30,47])$. Zooming in on the before and after response of "intention to adopt" of participants with higher levels of general trust in technology, we found that most had a lower score after the experience. This suggests that when promoting autonomous vehicles through pilot tests of partially automated vehicles, it is important to manage expectations of the vehicles' capabilities in the future.

\subsection{Limitations of the Study}

While the results of our exploratory pilot study indicate that experience with autonomous technology is an important factor in acceptance research, there are some limitations that must be considered when interpreting the findings. First, volunteers to participate in the study were recruited via online media. The invitation to take part in the study informed potential participants about the idea behind the pilot test. As participation might have been triggered by personal interest in autonomous vehicles or automotive technology in general, we consider self-selection bias a limitation of our study. This might have contributed to the overall positive attitude towards autonomous vehicles before the experience as attitudes of prospective early adopters may differ from the average mass-market consumer $[6,11,49]$. Second, we recruited a heterogeneous group of participants with respect to demographic characteristics, driving experience, and technology savviness; however, our study subjected a small sample of participants to the experience. This limitation is inherently linked to the constrained availability of the vehicle used for the test rides and the time-consuming approach of AV experience-centric experiments. Nonetheless, useful insights from experimental studies with small samples have added to the knowledge on $\mathrm{AV}$ user perceptions. For instance, in the study by Harb et al. [50], 13 
participants evaluated AV usefulness after AV ownership was simulated by a chauffeur driving participants to their desired destinations. Furthermore, the experiment by Ekman et al. [51] provided in-depth insights into the effect of AV driving styles (defensive vs. aggressive) on user trust by simulating a full automation experience for 18 participants with a wizard driver operating the vehicle during the experiment. Third, we did not subject a control group to the pretest and posttest measurement of perceptions, which prevents inter-group comparison and the assignment of a causal effect to the experience [24,52]. Last, inherent to the pretest-posttest setup of the experiment, interactive testing effects, where the subjection to the pretest triggers the participants to be more aware of what they experienced during the test ride, might have affected the participant's posttest responses. The experimental condition of the on-road experience with the automated vehicle partially combats this effect, as it reflects a closer resemblance to the situation to which we wish to generalise our results [53]. To overcome the effect of interactive testing and selection bias of the experimental group that limit the external validity of our findings, we suggest a replication of the field experiment with a larger sample and a control group to confirm the current findings of this study. We point out that offering incentives for participation at the recruitment stage could boost the overall participation rate and persuade more participants who are not necessarily interested in autonomous vehicles.

Additionally, the design of our experiment could be criticised for two reasons. First, while the selected route allowed for an on-road experience in regular traffic with the vehicle moving at high speed, the activation of the automated system that allowed participants to hand over the driving functions to the system was not possible for the entire duration of the ride. Second, the functionality of the level 2 automated vehicle is not comparable to that of a level 5 vehicle. Therefore, participants still relied in part on their imagination to form their expectations of fully autonomous vehicles. Experience with a level 4 or 5 vehicle that allows participants to engage in non-driving related tasks would better reflect the possibilities of full automation [1]. However, conducting this type of study in academic research is currently constraint by the available vehicle technology and traffic regulations that ensure the safety of drivers, passengers, and other road users. Last, since pretest and posttest measurements included the same survey items, it is possible that participants strove to be consistent in their answers before and after the experience. This is referred to as a main testing effect and occurs when the pretest affects the posttest [53]. Thus, even though our study intends to measure perceptions and intention to adopt fully autonomous vehicles, certain aspects of the experimental setup potentially limit the internal validity. Nonetheless, we believe the experience fostered a better understanding of autonomous technology and its possibilities for the future. To overcome the main testing effect of a one-shot study and stabilise the perceptions of participants towards autonomous vehicles, a longitudinal study in which the automated vehicle is available for daily use over a longer period of time could be considered as a track for future research (see [54]).

\subsection{Future Work}

The current study reports on a quantitative comparison of constructs related to the perception of fully autonomous personal vehicles, with questionnaire items rated on Likert scales, measured before and after participants experienced a test ride with a partially automated vehicle in a real traffic environment. We acknowledge that careful interpretation of the findings is advised related to the limitations discussed above. Therefore, we suggest the following approach for future research to verify the findings and add more in-depth insights to the existing knowledge. A longitudinal field experiment in which at least 30 participants, forming a heterogeneous group varying in terms of socio-demographic characteristics and driving experience, have access to an automated vehicle for daily use over a period of 5 to 7 days. We advise a mixed method approach for data collection to be able to capture both quantitative data on constructs related to AV user perceptions using questionnaires and qualitative data to provide more in-depth information on the underlying factors that affect perceptions conducting semi-structured interviews with 
the participants [51]. In parallel to the research with the experimental group, the same approaches for data collection should be applied to a control group of heterogeneous participants $(n>30)$ in order to allow inter-group comparison and assign a causal effect to the experience with the automated vehicle. We believe such an approach to be relevant in the context of user acceptance of autonomous vehicles as advanced driver assistance systems will steadily become more integrated in commercially available vehicles and the combination of quantitative and qualitative research can be useful to uncover the underlying factors that affect perceptions of AV usefulness, ease of use, and reliability.

\section{Conclusions}

This study focuses on the effect of a test ride in a partially automated passenger vehicle on the acceptance of the autonomous technology as a private vehicle user. We used a survey including determinants of technology acceptance to capture users' attitude towards and intention to adopt autonomous vehicles. A field experiment with 27 participants was conducted to assess changes in determinants before and after a test ride with a level 2 automated vehicle that allowed participants to experience automation related to the driving mode functions (steering and acceleration/deceleration) in a real traffic environment. We found that the test ride had a significant and substantial effect on result demonstrability, physical risk, functional risk, AV anxiety, perceived enjoyment, perceived ease of use, and attitude. This suggests that experience with automated technology fosters a better understanding of and positive perceptions towards autonomous vehicles. We also found a decrease in perceived usefulness and a non-significant increase in intention to adopt autonomous vehicles. However, since the experience had a significant positive effect on the majority of the measured constructs, our study indicates that large scale survey studies that do not require prior experience with automated driving capture an underestimation of the acceptance of autonomous vehicles.

Author Contributions: L.V. conceptualised the study design; L.V. and M.F. developed the questionnaire; M.F. collected and analysed the data; M.F. and E.R. produced the visualisation; M.F. wrote the manuscript; E.R. and L.V. edited the manuscript. Project supervision by L.V. All authors have read and agreed to the published version of the manuscript.

Funding: This research received no external funding.

Acknowledgments: The authors thank the participants that took part in the experiment and enabled this research to be possible. The authors are also grateful to the reviewers of the paper for their comments and suggestions to improve the paper.

Conflicts of Interest: The authors declare no conflict of interest.

\section{Abbreviations}

The following abbreviations are used in this manuscript:

$\begin{array}{ll}\text { ADAS } & \text { advanced driver-assistance systems } \\ \text { AV } & \text { autonomous vehicle } \\ \text { TAM } & \text { Technology Acceptance Model } \\ \text { TPB } & \text { Theory of Planned Behaviour } \\ \text { UTAUT } & \text { Unified Theory of Acceptance and Use of Technology }\end{array}$




\section{Appendix A. Survey Construct and Items}

Table A1. List of constructs, items, and references.

\begin{tabular}{|c|c|}
\hline Construct \& Items & Reference \\
\hline \multicolumn{2}{|l|}{ Perceived Ease of Use } \\
\hline \multicolumn{2}{|l|}{$\begin{array}{l}\text { I believe my interaction with an autonomous driving system will } \\
\text { be clear. }\end{array}$} \\
\hline $\begin{array}{l}\text { I believe that interacting with an autonomous driving system will } \\
\text { not require a lot of my mental effort. }\end{array}$ & \multirow{2}{*}{ Venkatesh and Bala [28] } \\
\hline I believe an autonomous driving system will be easy to use. & \\
\hline \multicolumn{2}{|l|}{$\begin{array}{l}\text { I believe it will be easy to get an autonomous driving system to do } \\
\text { what I want it to do. }\end{array}$} \\
\hline \multicolumn{2}{|l|}{ Perceived Enjoyment } \\
\hline \multicolumn{2}{|l|}{ I believe driving an autonomous vehicle will be fun. } \\
\hline \multicolumn{2}{|l|}{ I believe autonomous driving will be pleasant. } \\
\hline I believe autonomous driving will be monotonous. & Venkatesh and Bala [28] \\
\hline I believe driving an autonomous vehicle will be enjoyable. & \\
\hline
\end{tabular}

Autonomous Vehicle Anxiety

The expectation of driving an autonomous vehicle makes me nervous.

I believe I will feel at ease driving an autonomous vehicle.

Autonomous vehicles scare me.

Venkatesh and Bala [28]

I believe I will feel uncomfortable driving an autonomous vehicle.

\section{Perceived Usefulness}

I believe using an autonomous vehicle could increase my overall productivity.

I believe an autonomous vehicle is useful.

I believe an autonomous vehicle could enhance the effectiveness of my daily activities.

I believe using an autonomous vehicle could improve my performance in general.

Image

An autonomous vehicle represents a status symbol.

An autonomous vehicle improves my image.

I gain prestige from driving an autonomous vehicle.

Petschnig et al. [26]

An autonomous vehicle worsens my reputation.

An autonomous vehicle has a negative impact on my social status.

Result Demonstrability

I have no difficulty telling others about the results of an autonomous vehicle.

I believe I could communicate to others the consequences of an autonomous vehicle.

The results of using an autonomous driving system are apparent to me.

I would have difficulty explaining why driving an autonomous vehicle may or may not be beneficial. 
Table A1. Cont.

\begin{tabular}{lc}
\hline Construct \& Items & Reference \\
\hline $\begin{array}{l}\text { Comfort Benefit } \\
\text { An autonomous vehicle allows user's freedom for activities other } \\
\text { than driving. }\end{array}$ & $\begin{array}{c}\text { Items developed for } \\
\text { research context based } \\
\text { on Planing and } \\
\text { Britzelmaier [43] }\end{array}$ \\
$\begin{array}{l}\text { An autonomous vehicle allows for more efficient time use. } \\
\text { The use of an autonomous vehicle is time-saving. }\end{array}$ & Choi and Ji [30] \\
\hline $\begin{array}{l}\text { Trust } \\
\text { I believe autonomous vehicles are reliably. }\end{array}$ & \\
\hline $\begin{array}{l}\text { Physical Risk } \\
\text { I believe the use of autonomous vehicles will not pose a major } \\
\text { health risk. }\end{array}$ & Petschnig et al. [26] \\
$\begin{array}{l}\text { I believe autonomous vehicles are very safe for passengers. } \\
\text { I believe the use of autonomous vehicles is not very risky } \\
\text { for passengers. }\end{array}$ & \\
$\begin{array}{l}\text { I believe there exists low risk of injury for persons using } \\
\text { autonomous vehicles. }\end{array}$ & \\
$\begin{array}{l}\text { I believe autonomous vehicles represent a low accident risk } \\
\text { for passengers. }\end{array}$
\end{tabular}

Functional Risk

I believe autonomous vehicles work reliable.

I believe autonomous vehicles have a small number of product defects.

I believe autonomous driving systems work properly.

I believe no malfunctions occur while using autonomous

Petschnig et al. [26] driving systems.

I believe there are no functional problems while using autonomous vehicles.

\section{Security Risk}

The idea that autonomous driving systems may be introduced on a widespread scale worries me because of potential software hacking or other forms of misuse.

Item developed for research context based on Kyriakidis et al. [5]

\section{Subjective Norm}

People who influence my behaviour think that I should not use an autonomous vehicle.

People who are important to me think that I should use an autonomous vehicle.

People that mean a lot to me think that I should not use an autonomous vehicle.

People close to me think that I should not replace my conventional car with an autonomous vehicle.

People that mean a lot to me think that I should drive a conventional car as little as possible. 
Table A1. Cont.

\begin{tabular}{ll}
\hline Construct \& Items & Reference \\
\hline $\begin{array}{l}\text { Personal Norm } \\
\text { I feel a moral obligation to switch to autonomous vehicles, no } \\
\text { matter what other people do. }\end{array}$ & \\
I do not feel guilty when driving a conventional car myself instead & \\
$\quad$ of driving with an autonomous driving system. & Petschnig et al. [26] \\
I feel a moral obligation to drive an autonomous vehicle. & \\
$\begin{array}{l}\text { Personally, I feel that it is important to drive a conventional car } \\
\text { myself as little as possible. }\end{array}$ & \\
If I were to replace my car today I would feel a moral obligation to & \\
$\quad$ replace it for an autonomous vehicle. & \\
\hline $\begin{array}{l}\text { Attitude towards Autonomous Vehicles } \\
\text { I believe autonomous vehicles are good. }\end{array}$ & Petschnig et al. [26] \\
I dislike autonomous vehicles. & \\
I believe autonomous vehicles are appealing. & \\
I believe autonomous vehicles are favourable. &
\end{tabular}

Intention to Adopt Autonomous Vehicles

Assume autonomous vehicles are readily available on the market:

I will arrange to get an autonomous vehicle as soon as possible.

I do not intend to purchase an autonomous vehicle in the near future.

It is very likely that I will buy an autonomous vehicle.

I will not purchase an autonomous vehicle the next time I need a car.

Technology Anxiety

I am confident I can learn technology-related skills.

I have difficulty understanding most technological matters.

I feel apprehensive about using technology.

When given the opportunity to use technology, I fear I might damage it in some way.

I am sure of my ability to interpret technological output.

Technological terminology sounds like confusing jargon to me.

I have avoided technology because it is unfamiliar to me.

I am able to keep up with important technological advances.

I hesitate to use technology for fear of making mistakes I cannot correct.

General trust in technology

I believe that most technologies are effective at what they are designed to do.

A large majority of technologies are excellent.

Most technologies have the features needed for their domain.

I think most technologies enable me to do what I need to do.

My typical approach is to trust new technologies until they prove to me that I shouldn't trust them.

I usually trust a technology until it gives me a reason not to trust it.

I generally give a technology the benefit of the doubt when I first use it. 


\section{References}

1. SAE International. J3016: Taxonomy and Definitions for Terms Related to Driving Automation Systems for On-Road Motor Vehicles; Technical Report; SAE International: Warrendale, PA, USA, 2018.

2. Narayanan, S.; Chaniotakis, E.; Antoniou, C. Shared autonomous vehicle services: A comprehensive review. Transp. Res. Part C Emerg. Technol. 2020, 111, 255-293. [CrossRef]

3. Etzioni, S.; Hamadneh, J.; Elvarsson, A.B.; Esztergár-Kiss, D.; Djukanovic, M.; Neophytou, S.N.; Sodnik, J.; Polydoropoulou, A.; Tsouros, I.; Pronello, C.; et al. Modeling Cross-National Differences in Automated Vehicle Acceptance. Sustainability 2020, 12, 9765. [CrossRef]

4. Haboucha, C.J.; Ishaq, R.; Shiftan, Y. User preferences regarding autonomous vehicles. Transp. Res. Part C 2017, 78, 37-49. [CrossRef]

5. Kyriakidis, M.; Happee, R.; de Winter, J.C.F. Public opinion on automated driving: Results of an international questionnaire among 5000 respondents. Transp. Res. Part F Psychol. Behav. 2015, 32, 127-140. [CrossRef]

6. Liljamo, T.; Liimatainen, H.; Pöllänen, M. Attitudes and concerns on automated vehicles. Transp. Res. Part F Traffic Psychol. Behav. 2018, 59, 24-44. [CrossRef]

7. Payre, W.; Cestac, J.; Delhomme, P. Intention to use a fully automated car: Attitudes and a priori acceptability. Transp. Res. Part F Psychol. Behav. 2014, 27, 252-263. [CrossRef]

8. Rödel, C.; Stadler, S.; Meschtscherjakov, A.; Tscheligi, M. Towards Autonomous Cars: The Effect of Autonomy Levels on Acceptance and User Experience. In Proceedings of the 6th International Conference on Automotive User Interfaces and Interactive Vehicular Applications, Seattle, WA, USA, 17-19 September 2014; pp. 1-8. [CrossRef]

9. Schoettle, B.; Sivak, M. A Survey of Public Opinion about Autonomous and Self-Driving Vehicles in the U.S., the U.K. and Australia; Technical Report UMTRI-2014-21 (July); The University of Michigan Transportation Research Institute: Ann Arbor, MI, USA, 2014.

10. Schoettle, B.; Sivak, M. Public Opinion About Self-Driving Vehicles in China, India, Japan, the U.S., the U.K. and Australia; Technical Report UMTRI-2014-30 (October); The University of Michigan Transportation Research Institute: Ann Arbor, MI, USA, 2014.

11. Wang, S.; Jiang, Z.; Noland, R.B.; Mondschein, A.S. Attitudes towards privately-owned and shared autonomous vehicles. Transp. Res. Part F Traffic Psychol. Behav. 2020, 72, 297-306. [CrossRef]

12. Golbabaei, F.; Yigitcanlar, T.; Paz, A.; Bunker, J. Individual predictors of autonomous vehicle public acceptance and intention to use: A systematic review of the literature. J. Open Innov. Technol. Mark. Complex. 2020, 6, 106. [CrossRef]

13. Nordhoff, S.; van Arem, B.; Happee, R. Conceptual Model to Explain, Predict, and Improve User Acceptance of Driverless Podlike Vehicles. Transp. Res. Rec. J. Transp. Res. Board 2016, 2602, 60-67. [CrossRef]

14. Buckley, L.; Kaye, S.A.; Pradhan, A.K. Psychosocial factors associated with intended use of automated vehicles: A simulated driving study. Accid. Anal. Prev. 2018, 115, 202-208. [CrossRef] [PubMed]

15. Feys, M.; Rombaut, E.; Vanhaverbeke, L. Experience and acceptance of autonomous shuttles in the brussels capital region. Sustainability 2020, 12, 8403. [CrossRef]

16. Madigan, R.; Louw, T.; Wilbrink, M.; Schieben, A.; Merat, N. What influences the decision to use automated public transport? Using UTAUT to understand public acceptance of automated road transport systems. Transp. Res. Part F Traffic Psychol. Behav. 2017, 50, 55-64. [CrossRef]

17. Moták, L.; Neuville, E.; Chambres, P.; Marmoiton, F.; Monéger, F.; Coutarel, F.; Izaute, M. Antecedent variables of intentions to use an autonomous shuttle: Moving beyond TAM and TPB? Rev. Eur. Psychol. Appl. 2017, 67, 269-278. [CrossRef]

18. Nordhoff, S.; de Winter, J.; Madigan, R.; Merat, N.; van Arem, B.; Happee, R. User acceptance of automated shuttles in Berlin-Schöneberg: A questionnaire study. Transp. Res. Part F Traffic Psychol. Behav. 2018, 58, 843-854. [CrossRef]

19. Zoellick, J.C.; Kuhlmey, A.; Schenk, L.; Schindel, D.; Blüher, S. Amused, accepted, and used? Attitudes and emotions towards automated vehicles, their relationships, and predictive value for usage intention. Transp. Res. Part F Traffic Psychol. Behav. 2019, 65, 68-78. [CrossRef]

20. Hulse, L.M.; Xie, H.; Galea, E.R. Perceptions of autonomous vehicles: Relationships with road users, risk, gender and age. Saf. Sci. 2018, 102, 1-13. [CrossRef]

21. Hohenberger, C.; Spörrle, M.; Welpe, I.M. How and why do men and women differ in their willingness to use automated cars? The influence of emotions across different age groups. Transp. Res. Part A 2016, 94, 374-385. [CrossRef]

22. Bansal, P.; Kockelman, K.M.; Singh, A. Assessing public opinions of and interest in new vehicle technologies: An Austin perspective. Transp. Res. Part C Emerg. Technol. 2016, 67, 1-14.

23. Sweet, M.N.; Laidlaw, K. No longer in the driver's seat: How do affective motivations impact consumer interest in automated vehicles? Transportation 2020, 47, 2601-2634. [CrossRef]

24. Liu, P.; Xu, Z.; Zhao, X. Road tests of self-driving vehicles: Affective and cognitive pathways in acceptance formation. Transp. Res. Part A Policy Pract. 2019, 124, 354-369. [CrossRef]

25. Rahman, M.M.; Lesch, M.F.; Horrey, W.J.; Strawderman, L. Assessing the utility of TAM, TPB, and UTAUT for advanced driver assistance systems. Accid. Anal. Prev. 2017, 108, 361-373. [CrossRef]

26. Petschnig, M.; Heidenreich, S.; Spieth, P. Innovative alternatives take action-Investigating determinants of alternative fuel vehicle adoption. Transp. Res. Part A Policy Pract. 2014, 61, 68-83. [CrossRef]

27. Davis, F.D.; Bagozzi, R.P.; Warshaw, P.R. User Acceptance of Computer Technology: A Comparison of Two Theoretical Models. Manag. Sci. 1989, 35, 982-1003. [CrossRef] 
28. Venkatesh, V.; Bala, H. Technology Acceptance Model 3 and a Research Agenda on Interventions. Decis. Sci. $2008,39,273-315$. [CrossRef]

29. Acheampong, R.A.; Cugurullo, F. Capturing the behavioural determinants behind the adoption of autonomous vehicles: Conceptual frameworks and measurement models to predict public transport, sharing and ownership trends of self-driving cars. Transp. Res. Part F Traffic Psychol. Behav. 2019, 62, 349-375. [CrossRef]

30. Choi, J.K.; Ji, Y.G. Investigating the Importance of Trust on Adopting an Autonomous Vehicle. Int. J. Hum. Comput. Interact. 2015, 31, 692-702. [CrossRef]

31. Panagiotopoulos, I.; Dimitrakopoulos, G. An empirical investigation on consumers' intentions towards autonomous driving. Transp. Res. Part C Emerg. Technol. 2018, 95, 773-784. [CrossRef]

32. Xu, Z.; Zhang, K.; Min, H.; Wang, Z.; Zhao, X.; Liu, P. What drives people to accept automated vehicles? Findings from a field experiment. Transp. Res. Part C Emerg. Technol. 2018, 95, 320-334. [CrossRef]

33. Zhang, T.; Tao, D.; Qu, X.; Zhang, X.; Lin, R.; Zhang, W. The roles of initial trust and perceived risk in public's acceptance of automated vehicles. Transp. Res. Part C Emerg. Technol. 2019, 98, 207-220. [CrossRef]

34. Ajzen, I. The theory of planned behavior. Organ. Behav. Hum. Decis. Process. 1991, 50, 179-211. [CrossRef]

35. Venkatesh, V.; Morris, M.G.; Davis, G.B.; Davis, F.D. User Acceptance of Information Technology: Toward a Unified View. MIS Q. 2003, 27, 425-478. [CrossRef]

36. Venkatesh, V.; Thong, J.Y.; Xu, X. Consumer acceptance and use of information technology: Extending the unified theory of acceptance and use of technology. MIS Q. Manag. Inf. Syst. 2012, 36, 157-178. [CrossRef]

37. Leicht, T.; Chtourou, A.; Ben Youssef, K. Consumer innovativeness and intentioned autonomous car adoption. J. High Technol. Manag. Res. 2018, 29, 1-11. [CrossRef]

38. Madigan, R.; Louw, T.; Dziennus, M.; Graindorge, T.; Ortega, E.; Graindorge, M.; Merat, N. Acceptance of Automated Road Transport Systems (ARTS): An Adaptation of the UTAUT Model. Transp. Res. Procedia 2016, 14, 2217-2226. [CrossRef]

39. Rogers, E.M. The Diffusion of Innovations, 5th ed.; The Free Press: New York, NY, USA, 2003.

40. Fishbein, M.; Ajzen, I. Belief, Attitude, Intention, and Behavior: An Introduction to Theory and Research; Addison-Wesley: Reading, MA, USA, 1975.

41. Yuen, K.F.; Wong, Y.D.; Ma, F.; Wang, X. The determinants of public acceptance of autonomous vehicles: An innovation diffusion perspective. J. Clean. Prod. 2020, 270, 121904. [CrossRef]

42. Liu, N.; Nikitas, A.; Parkinson, S. Exploring expert perceptions about the cyber security and privacy of Connected and Autonomous Vehicles: A thematic analysis approach. Transp. Res. Part F Traffic Psychol. Behav. 2020, 75, 66-86. [CrossRef]

43. Planing, P.; Britzelmaier, B. Understanding consumer acceptance of advanced driver-assistance systems-A qualitative study on the German market. Int. J. Sales Retail. Mark. 2012, 1, 32-40.

44. Meuter, M.L.; Ostrom, A.L.; Bitner, M.J.; Roundtree, R. The influence of technology anxiety on consumer use and experiences with self-service technologies. J. Bus. Res. 2003, 56, 899-906. [CrossRef]

45. Mcknight, D.H.; Carter, M.; Thatcher, J.B.; Clay, P.F. Trust in a specific technology. ACM Trans. Manag. Inf. Syst. 2011, 2, 1-25. [CrossRef]

46. Field, A.; Miles, J.; Field, Z. Discovering Statistics Using R; Sage Publications Ltd.: London, UK, 2012.

47. Hohenberger, C.; Spörrle, M.; Welpe, I.M. Not fearless, but self-enhanced: The effects of anxiety on the willingness to use autonomous cars depend on individual levels of self-enhancement. Technol. Forecast. Soc. Chang. 2017, 116, 40-52. [CrossRef]

48. Nikitas, A.; Njoya, E.T.; Dani, S. Examining the myths of connected and autonomous vehicles: Analysing the pathway to a driverless mobility paradigm. Int. J. Automot. Technol. Manag. 2019, 19, 10-30. [CrossRef]

49. Hardman, S.; Berliner, R.; Tal, G. Who will be the early adopters of automated vehicles? Insights from a survey of electric vehicle owners in the United States. Transp. Res. Part D Transp. Environ. 2019, 71, 248-264. [CrossRef]

50. Harb, M.; Xiao, Y.; Circella, G.; Mokhtarian, P.L.; Walker, J.L. Projecting travelers into a world of self-driving vehicles: Estimating travel behavior implications via a naturalistic experiment. Transportation 2018, 45, 1671-1685. [CrossRef]

51. Ekman, F.; Johansson, M.; Bligård, L.O.; Karlsson, M.A.; Strömberg, H. Exploring automated vehicle driving styles as a source of trust information. Transp. Res. Part F Traffic Psychol. Behav. 2019, 65, 268-279. [CrossRef]

52. Skippon, S.M.; Kinnear, N.; Lloyd, L.; Stannard, J. How experience of use influences mass-market drivers' willingness to consider a battery electric vehicle: A randomised controlled trial. Transp. Res. Part A Policy Pract. 2016, 92, 26-42. [CrossRef]

53. Sekaran, U.; Bougie, R. Research Methods for Business: A Skill-Building Approach, 7th ed.; Wiley: Chichester, UK, 2016.

54. Jensen, A.F.; Cherchi, E.; Mabit, S.L. On the stability of preferences and attitudes before and after experiencing an electric vehicle. Transp. Res. Part D Transp. Environ. 2013, 25, 24-32. [CrossRef] 